\title{
Antibiotics modulate biofilm formation in fish pathogenic isolates of atypical Aeromonas salmonicida
}

\author{
Andrew P. Desbois (i) | Kira J. Cook | Elizabeth Buba
}

Institute of Aquaculture, Faculty of Natural Sciences, University of Stirling, Stirling, UK

\section{Correspondence}

Andrew P. Desbois, Institute of Aquaculture, Faculty of Natural Sciences, University of Stirling, Stirling, FK9 4LA, United Kingdom.

Email: ad54@stir.ac.uk

Funding information

EB is a PhD candidate supported by a scholarship from the Commonwealth Scholarship Commission.

\begin{abstract}
Atypical Aeromonas salmonicida causes furunculosis infections of non-salmonid fish, which requires antibiotic therapy. However, antibiotics may induce biofilm in some bacteria, which protects them against hostile conditions while allowing them to persist on surfaces, thus forming a reservoir for infection. The aim of this study was to determine whether atypical isolates of $A$. salmonicida increased biofilm in the presence of two antibiotics, florfenicol and oxytetracycline. A microtitre plate assay was used to quantify biofilm in the presence and absence of each antibiotic. Fifteen of 28 isolates formed biofilms under control conditions, while 23 of 28 isolates increased biofilm formation in the presence of at least one concentration of at least one antibiotic. For oxytetracycline, the most effective concentration causing biofilm to increase was one-quarter of that preventing visible bacterial growth, whereas for florfenicol it was one-half of this value. This is the first study to demonstrate that a bacterial pathogen of fish increases biofilm in response to antibiotics. Biofilm formation may increase the risk of re-infection in culture systems and this lifestyle favours the transmission of genetic material, which has implications for the dissemination of antibiotic-resistance genes and demonstrates the need for enhanced disease prevention measures against atypical $A$. salmonicida.
\end{abstract}

KEYWORDS

antimicrobial, aquaculture, ballan wrasse, cleaner fish, florfenicol, oxytetracycline

\section{1 | INTRODUCTION}

Aeromonas salmonicida is the aetiological agent of furunculosis, a potentially lethal infection of many species of fish that manifests typically as an ulcerative disease (Gudmundsdóttir, 1998; Menanteau-Ledouble, Kumar, Saleh, \& El-Matbouli, 2016; Wiklund \& Dalsgaard, 1998). Of the five subspecies of this Gram-negative pathogen, A. salmonicida subsp. salmonicida (i.e., typical isolates) largely causes infections in salmonid species, whereas the remaining four subspecies (i.e., the atypical isolates: achromogenes, masoucida, smithia and pectinolytica; MartinCarnahan \& Joseph, 2005) affect non-salmonid fish (MenanteauLedouble et al., 2016). Non-salmonid cleaner fish, such as ballan wrasse (Labrus bergylta Ascanius, 1767) and lumpfish (Cyclopterus lumpus Linnaeus, 1758), are cultured for deployment at Atlantic salmon (Salmo salar Linnaeus, 1758) farms as a biological approach to control populations of sea lice (mainly Lepeophtheirus salmonis Krøyer, 1837), which are exoparasitic crustaceans causing great concern for salmon producers (Brooker et al., 2018). However, being a relatively newly 
farmed species, where culture conditions continue to be optimised, means that cleaner fish can be susceptible to bacterial infections, and atypical isolates of $A$. salmonicida are one key pathogen responsible for disease outbreaks (Brooker et al., 2018; Hjeltnes, Bang-Jensen, Bornø, Haukaas, \& Walde, 2019). A raft of routine biosecurity measures is taken to prevent infections and protective vaccines are in development (Biering, Vaagnes, Krossoy, Gulla, \& Colquhoun, 2016; Erkinharju et al., 2017; Scarfe, Lee, \& O'Bryen, 2011), but antibiotics remain the only treatment option once a disease outbreak has occurred. Few antibiotics are approved for use in aquaculture in the United Kingdom and Norway where the cleaner fish are cultured, with florfenicol and oxytetracycline being two of the most commonly prescribed agents (The Norwegian Veterinary Institute, 2016; UK-VARSS, 2019).

Isolates of $A$. salmonicida are capable of attaching to solid materials and forming biofilms (Carballo, Seoane, \& Nieto, 2000; Dias, Borges, Saavedra, \& Simões, 2018), which are consortia of microorganisms typically surviving on a surface and surrounded by layers of non-cellular material, such as polysaccharides, lipids and nucleic acids, that provide a structure to protect against environmental challenges and insults (Davey \& O'Toole, 2000; Olsen, 2015). Bacteria in biofilms show altered gene expression and metabolism allowing them to persist in unfavourable conditions, including the presence of antibiotics and disinfectants (Bernier \& Surette, 2013; Davies, 2003; Olsen, 2015; Song, Duperthuy, \& Wai, 2016). Thus, biofilms can constitute a reservoir for infection and this can happen in aquaculture systems (Bourne, Høj, Webster, Swan, \& Hall, 2006; Karunasagar, Otta, \& Karunasagar, 1996; King et al., 2004). Of further concern, conditions in a biofilm also provide an environment conducive to the exchange of genetic materials such as plasmids, which may carry genes encoding for the mechanisms of antibiotic resistance and virulence (Dallaire-Dufresne, Tanaka, Trudel, Lafaille, \& Charette, 2014; Olsen, 2015; Talagrand-Reboul, Jumas-Bilak, \& Lamy, 2017). Interestingly, antibiotics and disinfectants can themselves induce certain species of bacteria to form biofilms (Hoffman et al., 2005; Kaplan, 2011; Ranieri, Whitchurch, \& Burrows, 2018; Tezel, Akçelik, Yüksel, Karatuğ, \& Akçelik, 2016; Waack \& Nicholson, 2018; Wang et al., 2010). Though various fish pathogenic bacteria can form biofilms, there have been no previous studies of whether antibiotics can induce or increase biofilm formation. Knowing whether fish pathogens form biofilms in response to antibiotics may provide support to pursue additional infection prevention measures and to develop alternatives to antibiotics for treatment.

Therefore, the aim of this present study was to determine whether biofilm of atypical isolates of $A$. salmonicida was increased in the presence of florfenicol or oxytetracycline.

\section{2 | MATERIALS AND METHODS}

\section{1 | Bacteria isolates and preparation of inoculums}

This present study used 28 isolates of atypical A. salmonicida collected during 2013-2019 from five sites in the United Kingdom, including a ballan wrasse hatchery, and identified according to the methods of Papadopoulou et al. (2020). Four isolates were from lumpfish, with the remainder deriving from ballan wrasse. The identity of each isolate was confirmed by conventional bacterial culture, phenotypic tests and sequencing of vapA and 16 S rRNA genes (Papadopoulou et al., 2020; Table S1). Colonies of atypical A. salmonicida isolates are typically cream in colour, translucent, circular and convex. Meanwhile, the cells are Gram-negative bacilli or short rods, non-motile, oxidase-positive, typically fermentative, resistant to vibrio static agent 0129 (10 and $150 \mu$ g per disc) and cause agglutination in a specific latex agglutination immunodiagnostic test for A. salmonicida (MONO-As; Bionor Laboratories AS) (Table S1). Routinely, all isolates were stored long term on cryobeads (Technical Service Consultants $\mathrm{Ltd}$ ) at $-70^{\circ} \mathrm{C}$ and were recovered on to tryptone soya agar (TSA; Oxoid) at $22^{\circ} \mathrm{C}$ for $72 \mathrm{hr}$ when required. Then, ca. $5 \mathrm{ml}$ of tryptone soya broth (TSB) in a universal was inoculated with 5-7 colonies from each plate and incubated at $22^{\circ} \mathrm{C}$ for $48 \mathrm{hr}$ at 140 revolutions per minute (RPM). Each culture was adjusted to an $A_{600}$ of $0.5 \pm 0.02$ with TSB, diluted 100 -fold in this medium and then used as inoculum in the biofilm assay.

\section{2 | Biofilm assay}

A microtitre plate biofilm assay modified from O'Toole (2011) was prepared to quantify the biofilm of each isolate formed in the absence of antibiotics and in the presence of different concentrations of florfenicol and oxytetracycline (Sigma-Aldrich Ltd). For each antibiotic, 96-well microtitre plates (flat-bottomed, Cell+; Sarstedt) were prepared to contain up to 10 doubling dilutions across the plate in triplicate, with TSB medium controls in columns 1 and 2 (each well contained a final volume of $150 \mu \mathrm{l}$ ). The concentration of florfenicol in column 12 on each plate was $8 \mathrm{mg} / \mathrm{L}$, but for oxytetracycline, where the isolates varied in susceptibility to this antibiotic (determined in preliminary trials; data not shown), the plates were prepared to contain 2, 8 or $32 \mathrm{mg} / \mathrm{L}$ in this column. Each well was inoculated with $10 \mu$ l of inoculum, except for the uninoculated control wells of column 1 that received $10 \mu$ TSB medium only. Batches of microtitre plates were sealed in plastic (zip-lock) bags to reduce evaporation and incubated at $22^{\circ} \mathrm{C}$ for $96 \mathrm{hr}$ without shaking (in a preliminary trial, 14/23 isolates formed more biofilm at $96 \mathrm{hr}$ than $72 \mathrm{hr}$; data not shown). After incubation, plates were examined to determine the minimum inhibitory concentration (MIC), which was the lowest concentration where bacterial growth was not visible by naked eye. Then, each well on the plate was washed four times with sterile water according to O'Toole (2011), before $150 \mu \mathrm{l}$ of $0.1 \%$ crystal violet (Sigma-Aldrich Ltd) was added to each well. The plate was incubated at room temperature for $15 \mathrm{~min}$ before the wells were washed four more times. Each plate was allowed to dry at room temperature for $3 \mathrm{hr}$, and then $150 \mu$ of $30 \%$ acetic acid (Fisher Scientific) was added to solubilize the crystal violet. This solution was pipetted into a fresh microtitre plate to allow the measurement of the $A_{550}$ of each well. 


\section{3 | Data analyses and statistical testing}

To determine whether each isolate formed a biofilm under control (i.e., non-antibiotic) conditions, a two-way Student's $t$ tests compared the mean $A_{550}$ values of the non-inoculated control wells $(n=6)$ with the inoculated control wells $(n=6)$ using QuickCalcs (www.graphpad.com; GraphPad).

To determine whether biofilm formation differed in the presence of sub-MIC concentrations of each antibiotic, two-way Student's $t$ tests compared the mean $A_{550}$ values of the inoculated control wells on each microtitre plate $(n=6)$ with each set of triplicate wells containing a sub-MIC concentration of antibiotic (a "subMIC concentration" of antibiotic is defined here to be those wells where bacterial growth was visible by examination with the naked eye). Holm's correction was applied to account for multiple comparisons, and $p<.05$ was considered to indicate a significant difference between groups.

\section{3 | RESULTS}

Fifteen of the 28 atypical A. salmonicida isolates formed biofilms to varying extents under control conditions, as indicated by a significant difference between mean $A_{550}$ values of the uninoculated and inoculated controls (Figure 1). The 13 isolates not forming a biofilm under control conditions included at least two isolates (i.e., SAIC-CF-022 and SAIC-CF-024) where biofilm was detected in one or more inoculated control wells (i.e., a high $A_{550}$ value) but where $A_{550}$ values appeared to vary sufficiently between the wells to explain the lack of significant difference compared with the uninoculated controls.

For 23 of the 28 isolates, exposure to at least one sub-MIC concentration of at least one antibiotic caused a significant increase in biofilm, either by the isolate being induced to form a biofilm when it had not under control conditions (10/13 isolates) or by increasing the overall quantity of biofilm formed (13/15 isolates; Figure 1, Figure S1, Figure S2). At least one sub-MIC concentration of oxytetracycline
FIGURE 1 Biofilm produced by 28 isolates of atypical $A$. salmonicida in the absence (white bars; $n=6$ ) and presence (grey bars; $n=3$ ) of florfenicol (a) or oxytetracycline (b). Note that the grey bars are the $A_{550}$ values of the antibiotic concentration that gave the greatest quantity of biofilm and was significantly different from the inoculated control (i.e., absence of antibiotic) by two-way Student's tests (Holm's corrected for multiple comparisons). Error bars are standard error. $\sim=$ indicates isolates that did not form biofilm in the absence of antibiotics under these incubation conditions (i.e., no significant difference compared with uninoculated control wells by two-way Student's $t$ test)
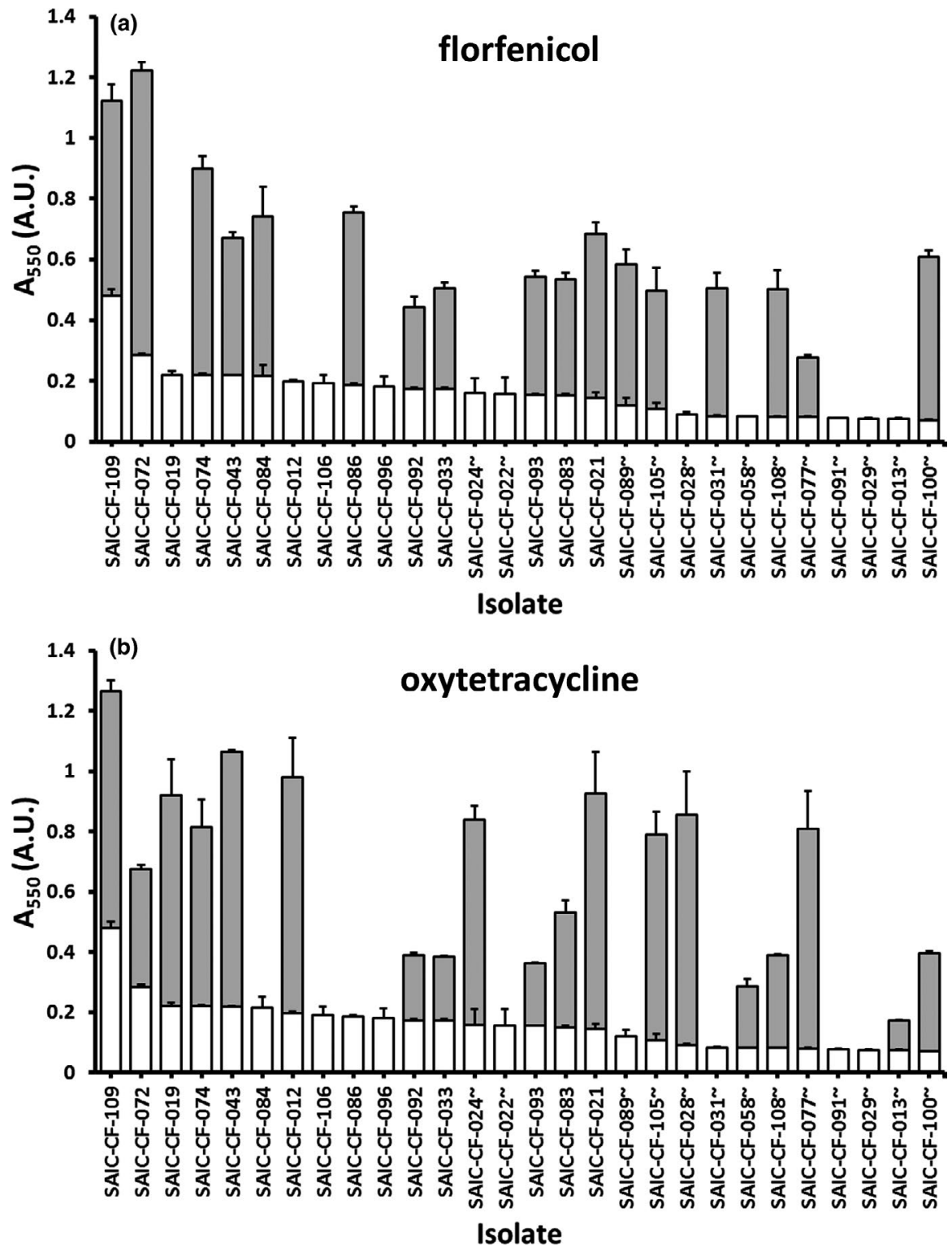
increased biofilm formation in 19/28 isolates, while at least one concentration of florfenicol increased biofilm formation in 17/28 isolates (Figure 1, Figure S1, Figure S2). For 13/28 isolates, both oxytetracycline and florfenicol each increased biofilm (Figure 1). For oxytetracycline, a concentration equal to the one-quarter of that preventing any visible growth by naked eye (i.e., the MIC as defined in this present study) was most effective at increasing biofilm formation, whereas for florfenicol it was one-half of this value (Table 1). Importantly, no visible growth was detected in any of the uninoculated control wells (data not shown).

For 10 isolates, a small number of sub-MIC concentrations of florfenicol (six isolates) and oxytetracycline (three isolates) or both (one isolate) caused slight, but significant, reductions in biofilm compared with the inoculated control wells, which most likely resulted from reduced bacterial growth decreasing the total biomass in the well (Figure S1, Figure S2).

\section{4 | DISCUSSION}

Antibiotics can induce or increase biofilm formation in various bacteria and, to our knowledge, this is the first report of such a response in a fish pathogen, specifically in this case A. salmonicida.

Biofilm formation by Aeromonas spp., including A. salmonicida, has been reported previously (Chenia \& Duma, 2017; Dias et al., 2018; Gavín et al., 2002; Hossain, Wickramanayake, Dahanayake, \& Heo, 2020; Igbinosa, Igbinosa, \& Okoh, 2015; Talagrand-Reboul et al., 2017). In this present study, more than half (15/28) of the atypical A. salmonicida isolates from cleaner fish formed biofilm in vitro in the absence of antibiotics, which concurs with a previous study of $A$. salmonicida collected from the mussel Mytilus coruscus where 8/14 isolates formed biofilm (Hossain et al., 2020). Meanwhile, Dias et al. (2018) reported all eight isolates of $A$. salmonicida from red deer and tawny owl were capable of forming biofilms in vitro. Thus, the present study confirms that $A$. salmonicida is capable of forming biofilm, which is important given that pathogenic bacteria in biofilm communities are potential sources of infection in aquatic animal

TABLE 1 Concentration of antibiotic causing greatest significant increase in biofilm in atypical $A$. salmonicida isolates as a fraction of the concentration inhibiting visible growth (i.e., the minimum inhibitory concentration [MIC]). For florfenicol, a concentration equal to one-half of the MIC increased biofilm the most for the greatest number of isolates ( $9 / 28$ isolates), whereas for oxytetracycline a concentration equal to one-quarter of the MIC increased biofilm for the most isolates (11/28 isolates). This table does not include isolates where biofilm was not increased significantly, or where an MIC was not determined (four isolates and one isolate for florfenicol and oxytetracycline, respectively)

\begin{tabular}{llccc} 
& \multicolumn{4}{l}{ Fraction of MIC (no. of isolates) } \\
\cline { 2 - 5 } Antibiotic & $1 / 16$ & $1 / 8$ & $1 / 4$ & $1 / 2$ \\
Florfenicol & & & 4 & 9 \\
Oxytetracycline & 1 & 2 & 11 & 4 \\
\hline
\end{tabular}

culture facilities (Bourne et al., 2006; Karunasagar et al., 1996; King et al., 2004). In aquaculture, biofilms form most apparently on nets, cages and the sides of tanks, and these have to be removed by thorough cleaning, but biofilms can also form on equipment and in pipes where they are far more difficult to disrupt.

Florfenicol and oxytetracycline, two antibiotics used commonly in aquaculture to treat bacterial infections of fish, each induced or increased biofilm in approximately two-thirds of the atypical A. salmonicida isolates. This response was isolate-dependent with some isolates increasing biofilm in the presence of just one of the antibiotics, while others responded similarly to both; the extent of increase in biofilm also differed between isolates and antibiotic concentrations. Antibiotics belonging to chloramphenicol and tetracycline families have been shown to induce biofilm in bacteria previously (Kaplan, 2011), but in regard of the specific antibiotics used in this present study, this is the first report of florfenicol causing such a response in a bacterium, although oxytetracycline has been shown to increase biofilm in the swine pathogen Streptococcus suis (Waack \& Nicholson, 2018). Ten of the 28 atypical A. salmonicida isolates only showed the potential to form biofilm in the presence of antibiotic, demonstrating that numerous culture conditions may need to be tested if seeking to determine the biofilm-forming potential of a particular bacterium. In addition to antibiotics, many other environmental factors can influence biofilm formation including temperature, nutrient availability, surface properties (e.g., charge, texture, material) and the presence of salt, chelating agents and membrane-perturbating compounds (Ansari, Jafri, Ahmad, \& Abulreesh, 2017; Cai, De La Fuente, \& Arias, 2013; Chenia \& Duma, 2017; TalagrandReboul et al., 2017). All of the isolates showed evidence for being able to form biofilm in vitro under at least one of the culture conditions employed in this present study, thus further confirming fish pathogenic isolates of atypical A. salmonicida to be capable of this phenotype. It is interesting to speculate whether the ability to form biofilm is more prevalent in fish pathogenic isolates of atypical $A$. salmonicida because a positive association between biofilm formation and the expression of virulence factors has been established for some bacteria (Naves et al., 2008; Rodrigues et al., 2018; Wand, Bock, Turton, Nugent, \& Sutton, 2012), though this is not universal.

The most effective concentrations of antibiotics causing the greatest increase in biofilm in the atypical $A$. salmonicida isolates were typically between one-half and one-quarter of that preventing visible growth of the bacterium, which is similar to observations reported for other bacteria (Kaplan, 2011). Increased biofilm may be a response to stress detected through the inhibition of growth, and antibiotic concentrations causing greatest stress will likely be close to those arresting growth completely (Bernier \& Surette, 2013). Bacteria in biofilms are better protected against environmental insults such as antibiotics, as far greater concentrations are needed to kill cells in a biofilm compared with a planktonic existence (Davey \& O'Toole, 2000; Olsen, 2015; Olson, Ceri, Morck, Buret, \& Read, 2002), while increased production of extracellular polymeric substances by bacteria growing in a biofilm provides one explanation because this can bind antibiotics to prevent penetration into the biofilm structure 
(Mulcahy, Charron-Mazenod, \& Lewenza, 2008; Olsen, 2015; Wang et al., 2019). Bacteria growing in biofilms show other alterations in behaviour and gene expression that can further explain decreased susceptibility to antibacterial agents including reduced metabolism (Knudsen, Fromberg, Ng, \& Gram, 2016; Olsen, 2015; Song et al., 2016; Sun, Chen, Lin, \& Lin, 2017). There are various proposed mechanisms by which antibiotic exposure increases biofilm, including the release of compounds such as DNA from damaged and dead bacteria that permit adherence to a surface or augment an established biofilm structure, and through induction of stress responses and increases in the production of secondary messengers that modulate gene expression such as cyclic di-guanosine monophosphate or the alarmone (p)ppGpp (Bernier \& Surette, 2013; Ranieri et al., 2018; Talagrand-Reboul et al., 2017). Notably, quorum sensing mediated by acylated homoserine lactones has been implicated in biofilm formation by Aeromonas spp., including A. salmonicida (Liu, Yan, Feng, \& Zhu, 2018; Talagrand-Reboul et al., 2017).

That two of the most commonly prescribed antibiotics used in aquaculture increased biofilm formed by $A$. salmonicida gives cause for concern because this response improves the survivability of the bacteria in the presence of the antibiotic, thus potentially driving persistence in culture systems. Moreover, this bacterial response may drive the selection and transmission of antibiotic-resistance genes, not only because biofilm conditions favour the transmission of genetic material such as plasmids that often contain antibiotic-resistance genes, but also because the architecture of a biofilm means bacteria within can be exposed to non-lethal antibiotic concentrations that permit selection for less susceptible strains (Mah \& O'Toole, 2001; Olsen, 2015; Talagrand-Reboul et al., 2017). Furthermore, Scornec, Bellanger, Guilloteau, Groshenry, and Merlin (2017) demonstrated that several antibiotics at sub-MIC concentrations could induce the transfer of mobile genetic elements between bacteria. Therefore, the induction of biofilm by sub-MIC concentrations of antibiotics may be an underappreciated mechanism favouring the selection and dissemination of antibiotic-resistance genes in fish pathogens and associated environmental bacteria.

There was variability between replicates of control cultures (i.e., not exposed to antibiotics), as well as cultures exposed to different concentrations of antibiotics, and this variability prevented the detection of statistical significance between certain groups. For example, variability in biofilm formation in replicate control wells of isolate SAIC-CF-106 $\left(A_{550}=0.196 \pm 0.026\right.$ [mean \pm standard error], range $=0.071$ to 0.252 ) meant differences between the inoculated control wells and the groups of wells containing sub-MIC concentrations of antibiotics failed to reach statistical significance, even though these isolates certainly seemed to increase biofilm formation in response to the antibiotics (e.g., isolate SAIC-CF-106, oxytetracycline at $0.03125 \mathrm{mg} / \mathrm{L}: \mathrm{A}_{550}=0.387 \pm 0.135$ ). Similarly, isolates SAIC-CF-022 and SAIC-CF-029 did not form biofilms in the presence of sub-MIC concentrations of antibiotics by our statistical analyses; however, a closer examination of the data reveals that biofilm was detected in some wells (isolate SAIC-CF-022, oxytetracycline at $0.015625 \mathrm{mg} / \mathrm{L}: \mathrm{A}_{550}=0.435 \pm 0.050$; isolate SAIC-CF-029, oxytetracycline at $0.03125 \mathrm{mg} / \mathrm{L}: \mathrm{A}_{550}=0.425 \pm 0.177$ ). This variability between wells with bacteria incubated under "identical" conditions is difficult to explain, and the reasons underlying this will not be determined by enhancing the power of statistical tests through increasing the number of replicates used, and more research needs to be performed to understand more completely these observations.

This present study was performed in vitro and under a specific set of conditions, and whether the observations described herein occur in aquaculture facilities under operating conditions remains to be confirmed. The environmental conditions on a fish farm, such as salt concentrations, nutrient concentrations and temperature, as well as the physical nature of the surface structures to which the bacteria can adhere, will exert a great influence on biofilm produced by the bacteria (Ansari et al., 2017; Carballo et al., 2000). Furthermore, natural biofilms consist of many different species of bacteria and other organisms and the effects of being in such a diverse community on biofilm formation in the absence or presence of antibiotics remain unknown. Practically, sub-MIC concentrations of antibiotics could be achieved in water or in the fish during and after therapeutic application in feed, as the agents could leach into the water (Xu \& Rogers, 1994) or pass through the fish unmetabolised (Leal, Santos, \& Esteves, 2019). This latter suggestion is of particular relevance in the culture of ballan wrasse, a stomachless species, as antibiotic dosing regimens used for this species are largely adapted from studies in salmonids that have grossly different gut physiology and longer gastrointestinal tracts for absorbing drugs (Le et al., 2019). Studies of concentrations of antibiotic residues in culture system water during and after therapy may help to quantify the risks around antibiotic resistance raised above.

This present study further highlights the need to implement better infection prevention strategies that reduce the need for antibiotics in aquaculture, including investment in enhanced biosecurity measures, alternatives to antibiotics (e.g., phage therapy), vaccines and additional prevention measures such as probiotics (Menanteau-Ledouble et al., 2016). Moreover, it may be that enhanced cleaning protocols would be beneficial after application of antibiotic or technology could be developed to eliminate residues from culture water during and after treatment to reduce antibiotic concentrations and the bacteria exposure window. Vaccines are a critical component of infection prevention in aquaculture, and numerous vaccines are available for a suite of fish diseases, including furunculosis caused by $A$. salmonicida (Adams, 2019; Menanteau-Ledouble et al., 2016). Indeed, autogenous vaccines are being applied to prevent outbreaks of atypical A. salmonicida in cleaner fish (Adams, 2019), but this present study further supports the need to develop an effective commercial vaccine.

To conclude, antibiotics are a critical tool in the veterinarian's armoury to treat infections of fish, but this present study provides further evidence for the negative impact of antibiotic use in aquaculture because exposure to these agents encouraged biofilm formation by a bacterial pathogen, which may increase the risk of re-infection in culture systems and favour the transmission of antibiotic-resistance genes. The findings strengthen the case for prudent antibiotic usage in aquaculture and support the introduction of enhanced infection prevention measures, including the development of protective vaccines. 


\section{ACKNOWLEDGEMENTS}

The isolates used in this study were collected at farms operated by Mowi Scotland and Scottish Sea Farms and deposited at Ridgeway Biologicals Ltd. Isolate collection was performed as part of the "Scaling up production and implementation of farmed cleaner fish in the Scottish salmon industry" project co-funded by the Scottish Aquaculture Innovation Centre, Mowi Scotland, Scottish Sea Farms and BioMar. Sincere thanks to Prof. Sandra Adams (University of Stirling) and Dr Tim Wallis (Ridgeway Biologicals Ltd) for providing access to the isolates.

\section{CONFLICT OF INTEREST}

The authors declare that there are no conflicts of interest.

\section{AUTHOR CONTRIBUTIONS}

APD conceived the study, designed the experiments and wrote the manuscript. KJC and EB conducted the experiments and provided critical input to the manuscript. All authors analysed the data and approved the final wording.

\section{DATA AVAILABILITY STATEMENT}

All data are available from the corresponding author on reasonable request.

\section{ORCID}

Andrew P. Desbois (DD https://orcid.org/0000-0001-6052-8761

\section{REFERENCES}

Adams, A. (2019). Progress, challenges and opportunities in fish vaccine development. Fish \& Shellfish Immunology, 90, 210-214. https://doi. org/10.1016/j.fsi.2019.04.066

Ansari, F. A., Jafri, H., Ahmad, I., \& Abulreesh, H. (2017). Factors affecting biofilm formation in in vitro and in the rhizosphere. In I. Ahmed \& F. M. Husain (Eds.), Biofilms in plant and soil health (1st ed., pp. 275-290). Hoboken: John Wiley \& Sons Ltd.

Bernier, S. P., \& Surette, M. G. (2013). Concentration-dependent activity of antibiotics in natural environments. Frontiers in Microbiology, 4, 20. https://doi.org/10.3389/fmicb.2013.00020

Biering, E., Vaagnes, O., Krossoy, B., Gulla, S., \& Colquhoun, D. J. (2016). Challenge models for atypical Aeromonas salmonicida and Vibrio anguillarum in farmed ballan wrasse (Labrus bergylta) and preliminary testing of a trial vaccine against atypical Aeromonas salmonicida. Journal of Fish Diseases, 39, 1257-1261.

Bourne, D. G., Høj, L., Webster, N. S., Swan, J., \& Hall, M. R. (2006). Biofilm development within a larval rearing tank of the tropical rock lobster, Panulirus ornatus. Aquaculture, 260, 27-38. https://doi.org/10.1016/j. aquaculture.2006.06.023

Brooker, A. J., Papadopoulou, A., Gutierrez, C., Rey, S., Davie, A., \& Migaud, H. (2018). Sustainable production and use of cleaner fish for the biological control of sea lice: Recent advances and current challenges. The Veterinary Record, 183, 383. https://doi.org/10.1136/vr.104966

Cai, W., De La Fuente, L., \& Arias, C. R. (2019). Transcriptome analysis of the fish pathogen Flavobacterium columnare in biofilm suggests calcium role in pathogenesis. BMC Microbiology, 19, 151. https://doi. org/10.1186/s12866-019-1533-4

Carballo, J., Seoane, R. M., \& Nieto, T. P. (2000). Adhesion of Aeromonas salmonicida to materials used in aquaculture. Bulletin of the European Association of Fish Pathologists, 20, 77-82.
Chenia, H. Y., \& Duma, S. (2017). Characterization of virulence, cell surface characteristics and biofilm-forming ability of Aeromonas spp. isolates from fish and sea water. Journal of Fish Diseases, 40, 339-350.

Dallaire-Dufresne, S., Tanaka, K. H., Trudel, M. V., Lafaille, A., \& Charette, S. J. (2014). Virulence, genomic features, and plasticity of Aeromonas salmonicida subsp. salmonicida, the causative agent of fish furunculosis. Veterinary Microbiology, 169, 1-7. https://doi.org/10.1016/j. vetmic.2013.06.025

Davey, M. E., \& O'Toole, G. A. (2000). Microbial biofilms: From ecology to molecular genetics. Microbiology and Molecular Biology Reviews, 64, 847-867. https://doi.org/10.1128/MMBR.64.4.847-867.2000

Davies, D. (2003). Understanding biofilm resistance to antibacterial agents. Nature Reviews Drug Discovery, 2, 114-122. https://doi. org/10.1038/nrd1008

Dias, C., Borges, A., Saavedra, M. J., \& Simões, M. (2018). Biofilm formation and multidrug resistant Aeromonas spp. from wild animals. Journal of Global Antimicrobial Resistance, 12, 227-234. https://doi. org/10.1016/j.jgar.2017.09.010

Erkinharju, T., Lundberg, M. R., Isdal, E., Hordvik, I., Dalmo, R. A., \& Seternes, T. (2017). Studies on the antibody response and side effects after intramuscular and intraperitoneal injection of Atlantic lumpfish (Cyclopterus lumpus L.) with different oil-based vaccines. Journal of Fish Diseases, 40, 1805-1813.

Gavín, R., Rabaan, A. A., Merino, S., Tomas, J. M., Gryllos, I., \& Shaw, J. G. (2002). Lateral flagella of Aeromonas species are essential for epithelial cell adherence and biofilm formation. Molecular Microbiology, 43, 383-397. https://doi.org/10.1046/j.1365-2958.2002.02750.x

Gudmundsdóttir, B. K. (1998). Infections by atypical strains of the bacterium Aeromonas salmonicida. Icelandic Agricultural Sciences, 12, 61-72.

Hjeltnes B., Bang-Jensen B., Bornø G., Haukaas A., Walde C. S. (Eds.). (2019). The health situation in Norwegian aquaculture 2018. Oslo: Norwegian Veterinary Institute.

Hoffman, L. R., D'Argenio, D. A., MacCoss, M. J., Zhang, Z., Jones, R. A., \& Miller, S. I. (2005). Aminoglycoside antibiotics induce bacterial biofilm formation. Nature, 436, 1171-1175. https://doi.org/10.1038/ nature03912

Hossain, S., Wickramanayake, M. V. K. S., Dahanayake, P. S., \& Heo, G.-J. (2020). Species identification, virulence markers and antimicrobial resistance profiles of Aeromonas sp. isolated from marketed hard-shelled mussel (Mytilus coruscus) in Korea. Letters in Applied Microbiology, 70, 221-229. https://doi.org/10.1111/lam.13266

Igbinosa, I. H., Igbinosa, E. O., \& Okoh, A. I. (2015). Detection of antibiotic resistance, virulence gene determinants and biofilm formation in Aeromonas species isolated from cattle. Environmental Science and Pollution Research, 22, 17596-17605. https://doi.org/10.1007/ s11356-015-4934-4

Kaplan, J. B. (2011). Antibiotic-induced biofilm formation. International Journal of Artificial Organs, 34, 737-751. https://doi.org/10.5301/ ijao. 5000027

Karunasagar, I., Otta, S. K., \& Karunasagar, I. (1996). Biofilm formation by Vibrio harveyi on surfaces. Aquaculture, 140, 241-245. https://doi. org/10.1016/0044-8486(95)01180-3

King, R. K., Flick, G. J. Jr., Pierson, D., Smith, S. A., Boardman, G. D., \& Coale, C. W. Jr. (2004). Identification of bacterial pathogens in biofilms of recirculating aquaculture systems. Journal of Aquatic Food Product Technology, 13, 125-133. https://doi.org/10.1300/J030v 13n01_11

Knudsen, G. M., Fromberg, A., Ng, Y., \& Gram, L. (2016). Sublethal concentrations of antibiotics cause shift to anaerobic metabolism in Listeria monocytogenes and induce phenotypes linked to antibiotic tolerance. Frontiers in Microbiology, 7, 1091. https://doi.org/10.3389/ fmicb.2016.01091

Le, H. T. M. D., Shao, X., Krogdahl, Å., Kortner, T. M., Lein, I., Kousoulaki, K., ... Sæle, $\varnothing$. (2019). Intestinal function of the stomachless fish, 
ballan wrasse (Labrus bergylta). Frontiers in Marine Science, 6, 140 https://doi.org/10.3389/fmars.2019.00140

Leal, J. F., Santos, E. B. H., \& Esteves, V. I. (2019). Oxytetracycline in intensive aquaculture: Water quality during and after its administration, environmental fate, toxicity and bacterial resistance. Reviews in Aquaculture, 188, 494-519. https://doi.org/10.1111/raq.12286

Liu, L., Yan, Y., Feng, L., \& Zhu, J. (2018). Quorum sensing asal mutants affect spoilage phenotypes, motility, and biofilm formation in a marine fish isolate of Aeromonas salmonicida. Food Microbiology, 76, 40-51. https://doi.org/10.1016/j.fm.2018.04.009

Mah, T. F. C., \& O'Toole, G. A. (2001). Mechanisms of biofilm resistance to antimicrobial agents. Trends in Microbiology, 9, 34-39. https://doi. org/10.1016/S0966-842X(00)01913-2

Martin-Carnahan, A., \& Joseph, S. (2005) Order XII. Aeromonadales ord. nov. In G. Garrity, D. J. Brenner, N. R. Krieg, J. R. Staley (Eds.), Bergey's manual of systematic bacteriology, Vol. 2 (The Proteobacteria), Part B (The Gammaproteobacteria) (2nd ed., pp. 556-586). New York: Springer.

Menanteau-Ledouble, S., Kumar, G., Saleh, M., \& El-Matbouli, M. (2016). Aeromonas salmonicida: Updates on an old acquaintance. Diseases of Aquatic Organisms, 120, 49-68. https://doi. org/10.3354/dao03006

Mulcahy, H., Charron-Mazenod, L., \& Lewenza, S. (2008). Extracellular DNA chelates cations and induces antibiotic resistance in Pseudomonas aeruginosa biofilms. PLoS Path, 4, e1000213. https:// doi.org/10.1371/journal.ppat.1000213

Naves, P., del Prado, G., Huelves, L., Gracia, M., Ruiz, V., Blanco, J., ... Soriano, F. (2008). Correlation between virulence factors and in vitro biofilm formation by Escherichia coli strains. Microbial Pathogenesis, 45, 86-91. https://doi.org/10.1016/j.micpath.2008.03.003

O'Toole, G. A. (2011). Microtiter dish biofilm formation assay. Journal of Visualized Experiments, 47, e2437. https://doi.org/10.3791/2437

Olsen, I. (2015). Biofilm-specific antibiotic tolerance and resistance. European Journal of Clinical Microbiology and Infectious Diseases, 34, 877-886. https://doi.org/10.1007/s10096-015-2323-z

Olson, M. E., Ceri, H., Morck, D. W., Buret, A. G., \& Read, R. R. (2002). Biofilm bacteria: Formation and comparative susceptibility to antibiotics. Canadian Journal of Veterinary Research, 66, 86-92.

Papadopoulou, A., Wallis, T., Ramirez-Paredes, J. G., Monaghan, S. J., Davie, A., Migaud, H., \& Adams, A. (2020). Atypical Aeromonas salmonicida vapA type $\mathrm{V}$ and Vibrio spp. are predominant bacteria recovered from ballan wrasse Labrus bergylta in Scotland. Diseases of Aquatic Organisms, 140, 47-54. https://doi.org/10.3354/dao03489

Ranieri, M. R., Whitchurch, C. B., \& Burrows, L. L. (2018). Mechanisms of biofilm stimulation by subinhibitory concentrations of antimicrobials. Current Opinion in Microbiology, 45, 164-169. https://doi. org/10.1016/j.mib.2018.07.006

Rodrigues, S., Paillard, C., Van Dillen, S., Tahrioui, A., Berjeaud, J.-M., Dufour, A., \& Bazire, A. (2018). Relation between Biofilm and virulence in Vibrio tapetis: A transcriptomic study. Pathogens, 7, 92. https://doi.org/10.3390/pathogens7040092

Scarfe, A. D., Lee, C.-S., \& O'Bryen, P. J. (2011). Aquaculture biosecurity: Prevention, control, and eradication of aquatic animal disease. Oxford: Blackwell Publishers.

Scornec, H., Bellanger, X., Guilloteau, H., Groshenry, G., \& Merlin, C. (2017). Inducibility of Tn916 conjugative transfer in Enterococcus faecalis by subinhibitory concentrations of ribosome-targeting antibiotics. Journal of Antimicrobial Chemotherapy, 72, 2722-2728. https:// doi.org/10.1093/jac/dkx202

Song, T., Duperthuy, M., \& Wai, S. N. (2016). Sub-optimal treatment of bacterial biofilms. Antibiotics (Basel), 5, 23. https://doi.org/10.3390/ antibiotics5020023

Sun, L., Chen, H., Lin, W., \& Lin, X. (2017). Quantitative proteomic analysis of Edwardsiella tarda in response to oxytetracycline stress in biofilm. Journal of Proteomics, 150, 141-148. https://doi.org/10.1016/j. jprot.2016.09.006
Talagrand-Reboul, E., Jumas-Bilak, E., \& Lamy, B. (2017). The social life of Aeromonas through biofilm and quorum sensing systems. Frontiers in Microbiology, 8, 37. https://doi.org/10.3389/ fmicb. 2017.00037

Tezel, B. U., Akçelik, N., Yüksel, F. N., Karatuğ, N. T., \& Akçelik, M. (2016). Effects of sub-MIC antibiotic concentrations on biofilm production of Salmonella Infantis. Biotechnology and Biotechnological Equipment, 30, 1184-1191. https://doi.org/10.1080/13102 818.2016.1224981

The Norwegian Veterinary Institute. (2016). Use of antibiotics in Norwegian aquaculture, report 22. The Norwegian Veterinary Institute, Oslo. Retrieved from https://www.vetinst.no/rappo rter-og-publikasjoner/rapporter/2016/use-of-antibiotics-in-norwe gian-aquaculture/_/attachment/download/03528c2b-8849-4a07bbe8-98358aceb176:f8e3f50d9442a35da57158ce9b5d0c43f16 5ce53/2016_22_Use\%20of\%20Antibiotics\%20in\%20Norwegia n\%20Aquaculture.pdf. Accessed 26 March 2020

UK-VARSS. (2019). UK veterinary antibiotic resistance and sales surveillance report (UK-VARSS 2018). Veterinary Medicines Directorate, Addlestone. Retrieved from https://assets.publi shing.service.gov.uk/government/uploads/system/uploads/ attachment_data/file/842678/PCDOCS-_1705145-v1-UKVARSS_2018_Report_2019_FINAL_v2.pdf. Accessed 26 March 2020

Waack, U., \& Nicholson, T. L. (2018). Subinhibitory concentrations of amoxicillin, lincomycin, and oxytetracycline commonly used to treat swine increase Streptococcus suis biofilm formation. Frontiers in Microbiology, 9, 2707. https://doi.org/10.3389/fmicb.2018.02707

Wand, M. E., Bock, L. J., Turton, J. F., Nugent, P. G., \& Sutton, J. M. (2012). Acinetobacter baumannii virulence is enhanced in Galleria mellonella following biofilm adaptation. Journal of Medical Microbiology, 61, 470-477. https://doi.org/10.1099/jmm.0.037523-0

Wang, C., Dong, D., Zhang, L., Song, Z., Hua, X., \& Guo, Z. (2019). Response of freshwater biofilms to antibiotic florfenicol and ofloxacin stress: Role of extracellular polymeric substances. International Journal of Environmental Research and Public Health, 16, 715. https:// doi.org/10.3390/ijerph16050715

Wang, Q., Sun, F. J., Liu, Y., Xiong, L. R., Xie, L. L., \& Xia, P. Y. (2010). Enhancement of biofilm formation by subinhibitory concentrations of macrolides in icaADBC-positive and -negative clinical isolates of Staphylococcus epidermidis. Antimicrobial Agents and Chemotherapy, 54, 2707-2711. https://doi.org/10.1128/AAC.01565-09

Wiklund, T., \& Dalsgaard, I. (1998). Occurrence and significance of atypical Aeromonas salmonicida in non-salmonid and salmonid fish species: A review. Diseases of Aquatic Organisms, 32, 49-69. https://doi. org/10.3354/dao032049

Xu, D., \& Rogers, W. A. (1994). Leaching loss from oxytetracycline medicated feeds. Journal of Applied Aquaculture, 4, 29-38. https://doi. org/10.1300/J028v04n01_03

\section{SUPPORTING INFORMATION}

Additional supporting information may be found online in the Supporting Information section.

How to cite this article: Desbois AP, Cook KJ, Buba E. Antibiotics modulate biofilm formation in fish pathogenic isolates of atypical Aeromonas salmonicida. J Fish Dis. 2020;43:1373-1379. https://doi.org/10.1111/jfd.13232 